\title{
Case Report: Paired/Dual Colloid Cysts in the Third Ventricle - A Discussion of Embryological Origin
}

\author{
SM Jay* and MR MacFarlane
}

Department of Neurosurgery, Christchurch Hospital, Christchurch, New Zealand

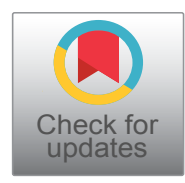

*Corresponding author: SM Jay, Department of Neurosurgery, Christchurch Hospital, Christchurch, New Zealand, Tel: +6433641217, Fax: +6433641030, E-mail: sharonj2@cdhb.govt.nz

\begin{abstract}
A 31-year-old male presented with a 4-month history of rising intracranial pressure. Initial computed tomography (CT) and then magnetic resonance imaging (MRI) showed moderate dilatation of the lateral ventricles with periventricular signal change, an indistinct third ventricle with an ill-defined lesion in the anterosuperior part of the third ventricle. At time of operation two paired/dual colloid cysts were found lying side-by-side in the third ventricle and obstructing both foramena of Munro. This is the first described case of paired/ dual colloids cysts in the third ventricle and re-ignites the debate as to the embryological origin of colloid cysts.
\end{abstract}

\section{Keywords}

Colloid cyst, Neuroepithelial cyst, Paraphysis, Third ventricle, Hydrocephalus, Neuroembryology

\section{Clinical Details}

A 31-year-old male presented to his local hospital with a 4-month history of recurrent mild headaches which became more severe in the week prior to admission, the severity of the headache reaching the point where he was unable to sleep and was associated with vomiting over the 24 hours before admission. Examination on admission showed he was fully alert and orientated (GCS 15/15) with no focal or abnormal neurological signs. Fundoscopy showed bilateral papilloedema with haemorrhages. An initial CT scan (Figure 1) showed moderate lateral ventricular dilatation with transependymal spread of cerebrospinal fluid (CSF) and a 2-3 $\mathrm{mm}$ hyperdense lesion in the anterosuperior aspect of the third ventricle - presumably a colloid cyst. The $4^{\text {th }}$ ventricle was normal. An MRI scan (Figure 2) showed indistinct anatomy in the anterosuperior as- pect of the $3^{\text {rd }}$ ventricle and the appearances were not typical of a colloid cyst. Given the acute hydrocephalus and that there was an obstructive lesion in the anterosuperior aspect of the $3^{\text {rd }}$ ventricle and that this was likely to be a colloid cyst we felt that direct surgery was undoubtedly indicated. The operation performed was a precoronal right frontal craniotomy and a transcortical approach via the right middle frontal gyrus and using microsurgical techniques to explore the anterosuperior aspect of the $3^{\text {rd }}$ ventricle via the right foramen of Munro with the expectation of finding and removing a colloid cyst. A colloid cyst was found and removed, the thin wall being breached with removal, with the cyst containing glairy fluid. Once this cyst was removed a second cyst of similar size and appearance was seen lying to the left of the removed cyst and this second cyst was also removed, great care being taken so as to not breach the cyst wall so this cyst was kept intact. Essentially the cysts had been were sitting side by side. The wall of the first (right) cyst and the intact second (left) cyst were subjected to microscopic pathological examination and both lesions had the typical appearances of colloid cysts with ciliated cuboidal epithelium and the second (left) cyst was confirmed as being intact/unruptured. The patient had an uncomplicated postoperative course with a satisfactory post-operative MRI showing resolving hydrocephalus and restoration of normal $3^{\text {rd }}$ ventricular anatomy. He was discharged from hospital neurologically intact on the $7^{\text {th }}$ postoperative day. At outpatient follow up 3 months postoperatively he was headache free, neurologically intact, had normal memory functioning and was back at work.

Citation: Jay SM, MacFarlane MR (2018) Case Report: Paired/Dual Colloid Cysts in the Third Ventricle - A Discussion of Embryological Origin. Int J Brain Disord Treat 4:023. doi.org/10.23937/24695866/1410023

Accepted: May 23, 2018: Published: May 25, 2018

Copyright: (C) 2018 Jay SM, et al. This is an open-access article distributed under the terms of the Creative Commons Attribution License, which permits unrestricted use, distribution, and reproduction in any medium, provided the original author and source are credited. 

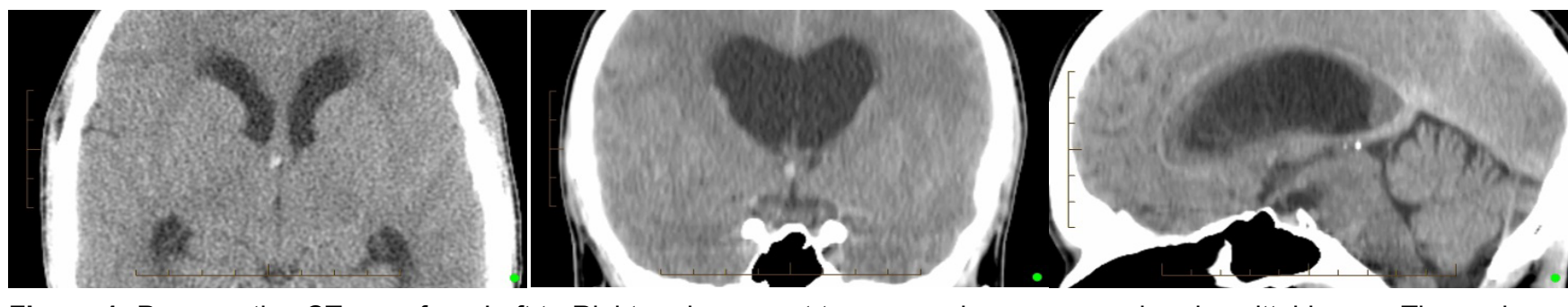

Figure 1: Preoperative CT scan from Left to Right- enlargement transverse image, coronal and sagittal image. These shows moderate lateral ventricular dilatation with transependymal spread of CSF and a 2-3 mm hyperdense lesion in the anterosuperior aspect of the third ventricle.

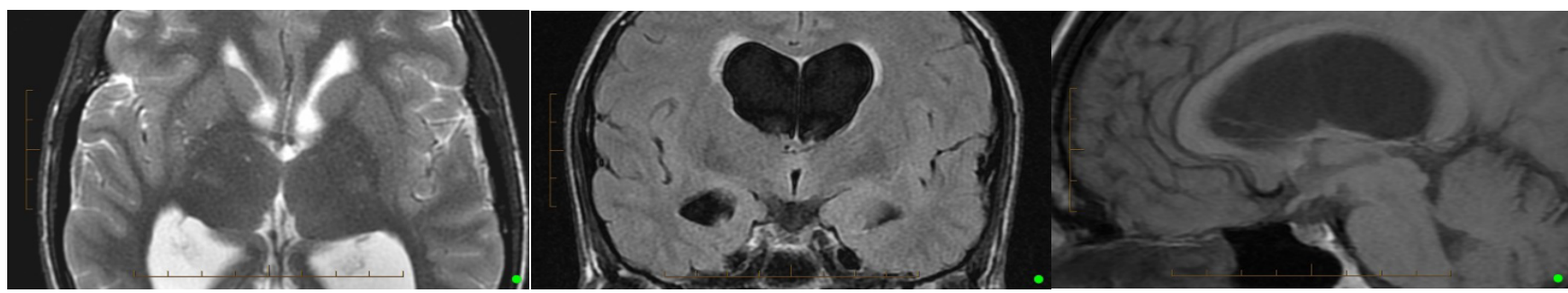

Figure 2: Preoperative MRI scan from Left to Right - Transverse T2, Coronal FLAIR \& Sagittal T1 (non-contrast). These show acute hydrocephalus with indistinct anatomy in the anterosuperior aspect of the $3^{\text {rd }}$ ventricle.

\section{Discussion}

There have been three documented case reports of multiple (two) colloid cysts - the most recent by Dahdaleh, et al. [1] with a colloid cyst in each of the third and lateral ventricles, the second such case report of this kind [2]. Parkinson and Childe [3] postulated the mechanism for multiple colloid cysts, in their case both cysts in the fourth ventricle, was either originating from the ependymal lining within the fourth ventricle itself or a migration - where the cyst detached from the third ventricle and travelled through the aqueduct to attach in the $4^{\text {th }}$ ventricle and increase in size to the point where they became symptomatic.

However, the authors present the first reported case of dual/paired colloid cysts in the $3^{\text {rd }}$ ventricle and obstructing the foramena of Munro. This re-opens the debate into the embryological origin of these benign lesions. There are three major documented theories as to their pathogenesis.

1. Derivation from embryonic paraphysis or ventricular roof (neuroectoderm): The paraphysis first described by Salenka in 1890 as 'a vesicle evaginating from the roof of the secondary forebrain or telencephalon and developing into a tubular structure [4]. The human paraphysis starts development from the telencephalic paraphyseal arch at $15-17 \mathrm{~mm}$ crown-rump length at approximately week 7 gestation. Kappers then found evidence of this between development stages $17-100 \mathrm{~mm}$ in 30 specimens and then postulated it degenerates at about the $100 \mathrm{~mm}$ stage (approx 3.5 months gestation). The U-shaped infolding of the diencephalic roof forms the velum interpositum [5] can undergo evagination into the space between the fornices or invagination into the third ventricle to form a colloid cyst- thus a colloid cyst is a midline structures by definition.

2. Developing from ependyma or choroid plexus: Kondziolka [6] used histochemical techniques to determine that colloid cyst epithelium is distinct, in terms of antigenic profile, from that of choroid plexus or ependyma, largely discounting this theory.

3. Ectopic respiratory/foregut epithelium: Lach, et al. [7] undertook immunohistochemical study of the colloid cyst epithelium from 21 colloid cysts and showed the immune phenytype of the epithelial lining to be similar to that of endoderm or ectoderm derived from respiratory or foregut origin. They compared this epithelium to the epithelium from Rathke's cleft cysts and also follicular cysts of the pituitary and these were also similar in nature. They suggested a common histogensis with these other neuroaxis cysts from the foregut-derived epithelia.

\section{Conclusion}

We believe our described case of bilateral/dual colloid cysts in the $3^{\text {rd }}$ ventricle is the first such documented case report with colloid cysts found in such close physical proximity, each sitting side by side in the $3^{\text {rd }}$ ventricle and each obstructing a foramen of Munro. Our case, combined with the previous reports of two more physically-separated colloid cysts, calls into question the embryo logical origin, certainly in relation to theory 1 above, that they are derived from the embryonic paraphysis or ventricular roof.

\section{Conflict of Interest}

The authors declare no conflict of interest. The authors alone are responsible for the content and writing of the paper. 


\section{References}

1. Dahdaleh NS, Dlouhy BJ, Kirby PA, Greenlee JD (2012) Unusual "double density" colloid cysts. Journal of Clinical Neuroscience 19: 612-614.

2. Maurice-Williams RS, Wadley JP (1998) Paired colloid cysts of the third and lateral ventricle. $\mathrm{Br} \mathrm{J}$ Neurosurg 12: 47-50.

3. Parkinson D, Childe AE (1975) Colloid cyst of the fourth ventricle; report of a case of two colloid cysts of the fourth ventricle. J Neurosurg 42: 353-357.
4. Kappers JA (1955) The Development of the paraphysis cerebri in man with comments on its relationship to the intercolumnar tubercle and its significance for the origin of cystic tumours in the third ventricle. J Comp Neurol 102: 425-509.

5. Ciric I, Zivin I (1975) Neuroepithelial (colloid) cysts of the septum pellucidum. J Neurosurg 43: 69-73.

6. Kondziolka D, Bilbao JM (1989) An innumohisotchemical study of neuroepithelial (colloid) cysts. J Neurosurg 71: 91-97.

7. Lach B, Scheithauer BW, Gregor A, Wick MR (1993) Colloid cyst of the third ventricle. J Neurosurg 78: 101-111. 